\title{
Understanding User Adaptation Strategies for the Launching of Facebook Timeline
}

\author{
Pamela Wisniewski \\ The Pennsylvania State University \\ University Park, PA 16802 \\ pam@pamspam.com
}

\author{
Heng Xu \\ The Pennsylvania State University \\ University Park, PA 16802 \\ hxu@ist.psu.edu
}

\author{
Yunan Chen \\ University of California, Irvine \\ Irvine, CA 92697 \\ yunanc@ics.uci.edu
}

\begin{abstract}
This paper applies coping theory to understand user adaptation strategies to major interface changes on Social Networking Sites (SNSs). Specifically, we qualitatively examine 1,149 user comments posted to the Facebook's official Timeline blog in order to get a large and unobtrusive sample of real Facebook users' perceptions about the launch of Timeline. Our data suggests a high level of stress associated with the transition to the new interface introduced by Timeline. We also found evidence which suggests that increasing users' perceptions of control over major interface changes may help facilitate user adaptation to these changes. This study offers valuable insights to SNSs for mitigating user stress and facilitating successful adaptation during major interface changes.
\end{abstract}

\section{Author Keywords \\ Facebook Timeline; User Adaptation; Change; Stress; Coping; Privacy}

\section{ACM Classification Keywords}

H.5.m. Information interfaces and presentation (e.g., HCI): Miscellaneous; K.4.1 Public Policy Issues: Privacy.

\section{INTRODUCTION}

At Facebook's September 2011 annual conference "F8," Mark Zuckerberg unveiled Facebook's new interface, "Timeline," as a "new way to express who you are" [5]. However, the rollout of Timeline was not the first time that Facebook made major interface changes. New Facebook features have been introduced consistently and frequently, such as the App Platform (2007), "New" Facebook (2008), "Like" button (2009), "New" Profile (2010), and most recently Graph Search (2013) [7]. These new features allow Facebook users to connect with more people and share more information than ever before [7].

Permission to make digital or hard copies of all or part of this work for personal or classroom use is granted without fee provided that copies are not made or distributed for profit or commercial advantage and that copies bear this notice and the full citation on the first page. Copyrights for components of this work owned by others than ACM must be honored. Abstracting with credit is permitted. To copy otherwise, or republish, to post on servers or to redistribute to lists, requires prior specific permission and/or a fee. Request permissions from Permissions@ acm.org.

CHI 2014, April 26 - May 01 2014, Toronto, ON, Canada

Copyright 2014 ACM 978-1-4503-2473-1/14/04...\$15.00.

http://dx.doi.org/10.1145/2556288.2557363
Yet, the launch of Timeline was unique for a few different reasons. First, Timeline drastically changed how Facebook users used Facebook. Now, instead of one's Wall being a place to share and connect with friends, Timeline was meant to be a searchable, personal archive for historical life events [5]. Second, Timeline was one of the most controversial Facebook interface changes of all time. Sodahead conducted a survey of over 1,000 Facebook users and $86 \%$ of their respondents declared that they wanted Facebook to rollback Timeline [14]. A possible reason for the momentous backlash against Timeline was that so many major interface changes were rolled out in one release. In addition to changes specific to Timeline, Facebook also included additional changes in this release; they added a News Ticker that posted friends' Facebook activities using a real time, scrolling sidebar [9]; changed the sort order for the News Feed [9]; and modified other features, such as the chat interface [12].

Given these unique characteristics, we use the launch of Facebook Timeline as a case to examine how existing social networking site (SNS) users adapt to major interface changes within an established SNS environment. Past research has primarily focused on the initial adoption [3], subsequent use [10], and non-use of SNSs [1]. Very little research has studied how existing users respond to major SNS interface changes. To fill this gap, we study how Facebook users respond to the launching of Facebook Timeline. In particular, we examined 1,149 comments posted to the Facebook's official Timeline Blog between September 2011 and April 2012. We use coping theory [11] to understand users' perceptions and observed a significant amount of stress associated with the switch to Facebook Timeline. We describe why this stress occurred and how Facebook users coped in order to reduce stress. We conclude with suggestions for how SNSs could mitigate user stress and facilitate user adaptation to major interface changes in the future.

\section{BACKGROUND}

\section{User Adaptation}

User adaptation is defined as "the cognitive and behavioral efforts performed by users to cope with significant information technology events that occur" [2]. Most of the work that has focused on user adaptation to new technologies has been contextualized within organizational settings. For example, Beaudry and Pinsonneault applied 
coping theory [11] to the introduction of new information technologies within companies [2]. However, organizations often have goals, policies, and culture that influence the adaptation process. In contrast, SNS websites are communities designed mainly for personal use and end user goals are more likely driven by the individual and influenced by one's social circles. This distinct difference makes adapting technologies in social media settings an interesting, new area of study. Yet, very few studies have examined user adaptation to technological changes within the context of social media. Previous research has highlighted Facebook users' reactions to new features, such as New Profile [17] and Friendship Pages [13]. However, these studies focused solely on the privacy concerns users perceived with these interface changes instead of the broader context of user adaptation to the changes themselves. To our knowledge, our research is one of the first to apply coping theory [11] to examine how users react to major interface changes within SNSs.

\section{Conceptual Framework}

Lazarus and Folkman's seminal work on Stress, Appraisal, and Coping [11] is one of the most widely accepted theories of the coping process [2]. Because their theory deals directly with how individuals cope with stress caused by environmental changes, we felt that it was an appropriate and relevant theory in which to frame our analysis. Figure 1 highlights the main tenets of coping theory [11]. Stress is defined as a relationship between a person and the environment that is perceived to be taxing, exceeding of one's resources, or detrimental to one's well-being [11]. Change within the environment is one key source of stress because it requires the individual to adapt to that new environment [11].

When a change occurs within one's environment, an individual asks him or herself, "How does this change affect me?" This assessment is called a primary appraisal of the situation, which can be positive, stressful, or irrelevant [11]. A positive appraisal is construed as a benefit for the individual while an irrelevant appraisal means that the individual is indifferent to the change [11]. Stress appraisals occur when individuals believe that the change negatively affects them; stress appraisals can be further classified into sub-categories: 1) loss or harm denotes that the individual has already sustained some damages; 2) threats are anticipated harm or loss that may occur in the future; and 3) challenges acknowledge the potential for growth or opportunity due to the change [11].

If an individual perceives a change as stressful, the next question they ask themselves is, "What can I do about this change?" This cognitive thought process is called a secondary appraisal [11]. Generally, there are two types of secondary appraisals: Individuals who perceive that they have high levels of control believe that they possess the necessary resources to address the change in the environment and reduce stress. In contrast, low perceived

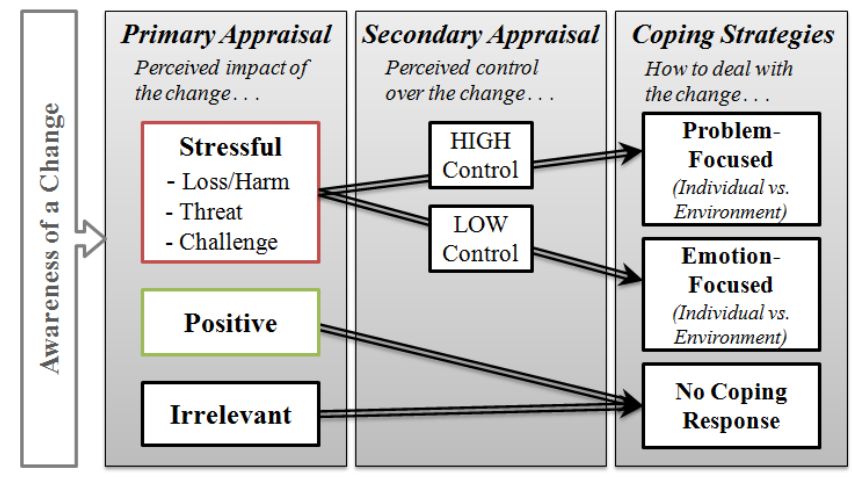

Figure 1: Conceptualization of Coping Theory

control is associated with individuals who believe that there is little or nothing that they can do about the change.

Coping strategies are cognitive and behavioral efforts an individual takes to reduce stress caused by environmental change [11]. They can either be emotion-focused or problem-focused. Emotion-focused coping mechanisms focus on an individual's internal emotional regulation as a means to adapting to environmental change. Coping strategies tend to be emotion-focused when individuals perceive a low level of control over the environment [11]. Problem-focused coping strategies tend to be action-based and externally focused on trying to find ways to change the environment to suit the individual's needs. Therefore, coping strategies are essentially means of negotiating an equilibrium between the individual and the environment as to reduce stress [11]. We use coping theory, as defined above, to better understand how Facebook users appraised and coped with the transition to Facebook Timeline.

\section{Facebook Timeline}

Timeline became publicly available as an opt-in feature to Facebook users on December 15, 2011 [5]. On May 21, 2012, Timeline became a mandatory upgrade for all users [4]. Facebook gave users a 7-day grace period so that they could remove, hide, or customize the visibility of old posts before they went live on Timeline [6]. Some of the main changes bundled into the launch of Timeline included [6]:

- Ability for users and friends to access past posts by date, as opposed to having to scroll through a reverse chronological list of historical posts

- Ability for users to add content anywhere on the Timeline of posts (life events, photos, etc.)

- Ability to highlight certain life events across the new two-column layout

- Inline privacy controls to remove, customize visibility, or hide anything on the Timeline

- Groupings of profile information at the top of a user's Timeline (photos, likes, apps, etc.) and a cover photo

- An activity log that allows users to view and share all of their Facebook activities (posts, likes, etc.) 
Prior to the launch of Timeline, Facebook released an official Timeline blog [5] to introduce various new features. This blog also allowed users to ask questions and share their opinions about Timeline via comments. The blog was first launched on September 22, 2011, and the last user comment posted to the blog, before user commenting was deactivated, was on April 2, 2012 [5].

\section{METHODOLOGY}

\section{Data Collection and Sampling}

On April 19, 2012, we manually collected the first 100 pages of Facebook user comments that were posted on the Facebook Timeline Blog [5]. Since commenting ceased on April 2, 2012, we were able to sample from the full set of 4,439 user comments that were ever posted to this blog. The most popular Facebook user comments (based on number of Likes) were posted first and in descending order of Likes, along with all direct replies to those comments. Therefore, we collected a total of 84 of the most popular original comments and 1,065 comments that replied to this set of 84 most popular comments. Our final dataset for analysis contained 1,149 comments from a total of 676 unique Facebook users. Based on names and profile pictures, our sample consisted of 288 females and 369 males, with the remaining users unidentifiable by gender. Comments suggested that users ranged from technology novices to experts. The average number of comments made per user was 1.7 with a standard deviation of 1.89 comments. The most frequent commenter posted a total of 21 times. We discarded 191 comments from our data set due to lack of relevance. These comments either lacked sufficient context or consisted of flaming wars or spam.

\section{Qualitative Coding}

We based our qualitative coding schema on coping theory [11]. Therefore, we coded based on the following theoretical constructs: Primary Appraisal (Positive, Stressful, Irrelevant); Stressful Type (Harm/Loss, Threat, Challenge); Reason (Open coded); Secondary Appraisal (Low-Control, High-Control); Coping Type (ProblemFocused, Emotion-Focused); Coping Focus (User, Environment); and Coping Strategy (Open coded). In cases where comments contained multiple codes for one category (e.g. multiple coping strategies), we double counted these comments across the codes. Also, additional codes emerged as we applied coping theory to the unique context of user adaptation to Facebook Timeline.

After the primary researcher developed a standard code book using coping theory, she then trained two other coders. The comments were divided equally among the three coders. As new codes emerged, the three coders defined and shared their new codes with the other coders in order to ensure consistency. We calculated a metric for inter-rater reliability (IRR) by having all three coders code a subset of 100 comments; the secondary coders' levels of agreement with the primary coder were $95 \%$ and $83 \%$. The combined IRR for all three coders was $81 \%$. After all the data were coded, the primary researcher reviewed all of the codes and resolved any conflicts by collaborating with the secondary coders. Data coding and analysis were performed using Microsoft Excel® data filters, pivot tables, and graphs.

\section{RESULTS}

Primary Appraisal: How does this change affect me?

Individuals cognitively assess how changes in the environment personally affect them; such an assessment is called a primary appraisal [11]. A total of 752 comments (78\%) contained a primary appraisal about how Facebook users perceived the impact of Timeline. Of the primary appraisals, $64 \%$ represented stress appraisals, $20 \%$ positive appraisals, and $16 \%$ suggested that the change was irrelevant to the Facebook user. We will address each type of primary appraisal in descending order of emergence in our data set. We first discuss stress appraisals (Loss/Harm $54 \%$, Threats - 25\%, and Challenges - 21\%), followed by positive appraisals and irrelevant appraisals.

\section{Stress Appraisals: Loss/Harm}

In coping theory, loss or harm denotes that the individual has already sustained some damages [11]. Even though coping theory groups loss and harm in the same category, we found a distinct difference between loss and harm in our data. In our research context, loss tended to result from the feeling that something a Facebook user once had has been taken away. Harm, on the other hand, was a direct negative consequence that was associated with Timeline. Loss represented approximately 53\% of primary stress appraisals while actual harm was less than $1 \%$ of all stress appraisals. Harm most commonly resulted from unintentional privacy breaches. For example, one user shared that her homosexual friend "has come out to the world when he didn't want to," because of Timeline.

Since loss represented over half of all stress appraisals, we focused on analyzing why Facebook users perceived stress due to a sense of loss. The top five reasons Facebook users expressed a sense of loss included loss of familiarity (29\%), control (25\%), intended use (18.5\%), simplicity (17\%), and user satisfaction $(10.5 \%)$, respectively.

Loss of familiarity was the strongest lament of Facebook users who posted on the Timeline blog. Thirty percent of loss appraisal comments just wanted Facebook to bring the "old" Facebook back. These Facebook users generally were opposed to change and expressed a sense of loss because the new interface simply was not the old one that they were used to. This sentiment is summed up by the first commenter's post that received 3,412 Likes:

"shut the eff up and bring the old facebook back," Harmoni, Comment \#1, 3412 Likes 
Loss of control was the second highest reason for loss appraisals. These Facebook users were often upset that Facebook did not give them the choice to opt-in or opt-out of Timeline. These users tended to believe that, as Facebook's users, they should have the final say before Facebook releases new changes:

"I don't mind change...but I'd like the option to change it back if I don't like it... shouldn't FB at least give us options instead of forcing it on us?" Deanne, Comment \#723, 321 Likes

Loss of intended use surfaced as the main stressor in $18.5 \%$ of the loss appraisals. A number of comments reflected user frustration that Facebook had completely changed how the site was meant to be used. Many users saw Facebook as a place to share and connect with their friends, and they were uncomfortable that Timeline changed that purpose by making it a personal archive for old posts:

"I agree with you this totally sucks!!! Now we need to find a social page because our old social page has become a virtual diary/scrapbook.” Kathy, Comment \#681

Other Facebook users were upset that features that they had in "old" Facebook were taken away or, in some cases, new features that they did not want were added. Interestingly enough, however, most of these posts tended to have very little to do with the main changes attributed to Timeline itself. Instead, these complaints were about additional interface changes that were bundled together with Timeline. Facebook users often did not know the conceptual difference between these features and Timeline. For example, numerous complaints surfaced about the sort order of one's News Feed, the addition of the News Ticker (a.k.a. "stalker bar"), and the new chat interface:

"It's been three months but i still hate this new facebook specially the news feed \& ticker!!!!” Asif, Comment \#223

Loss of simplicity was another type of loss appraisals. These users were stressed because Facebook no longer seemed to have the simple interface that they used to be able to easily navigate. They felt that the new Facebook was too complex and cumbersome:

"Why can't you guys just leave Facebook the way it was... People loved it simple and now with all this new stuff your just pushing people towards other sites..." Jacob, Comment \#898, 92 Likes

Loss of user satisfaction was the final reason Facebook users gave for making a loss appraisal. Some comments specifically criticized the new look and feel of Timeline while others expressed a more generalized dislike:

" $i$ know how to use it. im just not enjoying it," Dustin, Comment \#736, 8 Likes
Stress Appraisals: Threats

Threats are anticipated harm or loss that may occur in the future [11]. Twenty-five percent of stress appraisals were made because Facebook users perceived Timeline as an imminent threat to their personal privacy. We observed that intrusiveness, or concern over invasions into one's life [15], was the top privacy threat. "Jay" was the most frequent blog commenter, and he had developed quite a following of Facebook users who agreed with him that Timeline promoted stalking and that Facebook was trying to push an agenda for the erosion of personal privacy:

"This sounds like it's tailor made for stalking," Jay, Comment \#274, 1,873 Likes

Facebook users also felt threatened by the new aggregation [15] of their personal information into one place. This was especially true for how Timeline displayed personal profile information at the top of one's profile:

"Plus seriously, like look when we comment look beside our names? U can see our location, [what] schools we go to an where we work, just little things like that suck! really come on, its not as safe i hate it," Christina, Comment \#92

Other Facebook users were concerned about the increased accessibility [15] to their personal information:

"There are some people who're trying to make a change in their lives and move on from the past. This new Timeline stuff isn't helping. you're only opening your past to the public. I wouldn't be complaining if they could have some privacy settings on this but not even one? Really? You're gonna let the whole world access your past like that?" Tony, Comment \#218

While this user was misinformed about how the new privacy settings actually worked, he was accurate in his assessment that the new design threatened personal privacy by increasing the potential longevity of past posts. Even though Timeline did not actually change what information could be accessed, they did make past posts more accessible by allowing users to search for past posts by year.

\section{Stress Appraisals: Challenges}

Challenges are stress appraisals that acknowledge the potential for future opportunities after certain difficulties have been overcome [11]. Challenges represented about $21 \%$ of the stress appraisals. These comments reiterated that the change to Timeline was indeed stressful. However, they did so with the glint of a silver lining and hope that, in time, Timeline would prove to be a positive change.

The learning curve associated with the interface changes introduced with Timeline represented $60 \%$ of the challenge appraisals. In many cases, Facebook users were well aware that they would have to learn the new Facebook privacy settings in order to protect themselves from Timeline's enhanced capabilities for accessing someone's past posts: 
" $u$ decide what is seen on ur timeline ... a lot of privacy settings has been [added], every single part of your timeline can be protected ..." Amy, Comment \#456

However, many Facebook users acknowledged that using the new privacy settings was not a trivial task:

"I am in a huge learning curve "The Facebook Blog" videos are re-running in my head, I am searching for [a way] to [toggle] for all these new changes over and over in my dreams and night mares, I will survive..." Sandra, Comment \#174

Adapting to change (31\%) was the second most discussed type of challenge. "Zac" was the first one to reply to Harmoni's "shut the eff up," comment, and he received even more likes than the original poster:

"the old facebook was the new facebook once. the world changes, get used to it, " Zac, Comment \#2, 4,599 Likes

Quite a few replies tagged Zac directly, agreeing with his post. These Facebook users tended to take an evolutionary viewpoint where they accepted that Facebook had to change in order to improve. This viewpoint was in direct antithesis to the loss, stress appraisals that generally felt that change was bad. These users often acknowledged the considerable amount of stress that comes with learning how to adapt to change, but they believed it was worth the efforts.

\section{Positive Appraisals}

Twenty percent of Facebook comments suggested that the change to Timeline was a positive event. Interestingly, the most common reason (29\%) for this positive primary appraisal was that these users believed Timeline actually increased their level of privacy control:

"facebook timeline has better security on privacy. even every item on your profile info can be set one by one," Day, Comment \#522

Other common reasons for positive appraisals included seeing Timeline as a privilege (19\%), preferring the new interface $(18 \%)$, believing that innovation is necessary for Facebook's survival (16\%), liking the new organization of the website $(11 \%)$, and being able to share more effectively with friends $(7 \%)$.

\section{Irrelevant Appraisals}

Sixteen percent of Facebook users believed that the change to Timeline was irrelevant to them and other users. For the most part, these Facebook users were directly responding to others' stressful appraisals of Timeline as a privacy threat. The majority (83\%) of these comments argued that the change did not matter because Timeline did not share any information that SNS users had not already shared in past. They argued that Timeline had no effect on privacy because it was the individuals' personal responsibility (just like before) to make good decisions about what they chose to disclose or not disclose on Facebook.

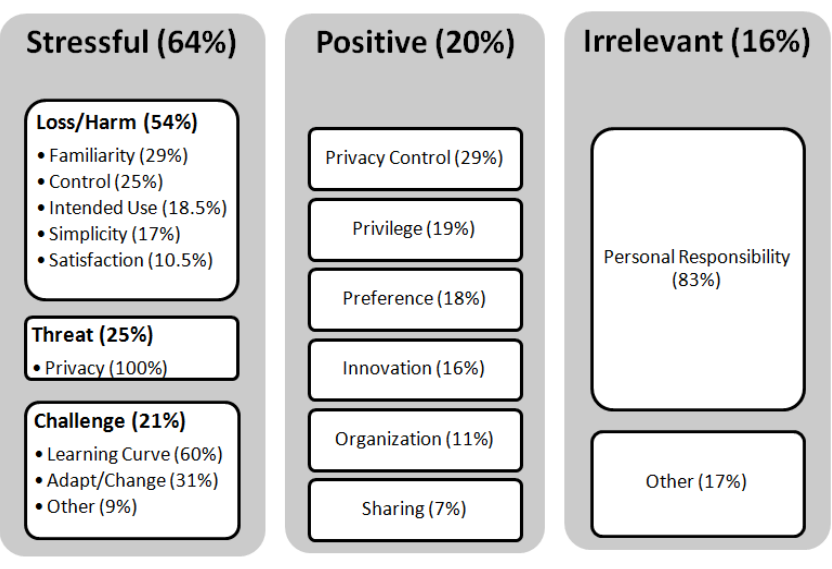

Figure 2: Summary of Primary Appraisals

"Well, you can choose what to include and what not to include. It's the same as always. Not to be the devil's advocate, but all the information doesn't pop up on Facebook by magic; it's there because you obviously chose to share it." Angela, Comment \#360

Figure 2 summarizes the full set of primary appraisals within our data set and the reasoning behind each. It is clear from this analysis that users' assessments of Timeline varied drastically and, at times, were contradictory of one another. This highlights how primary appraisals were based on individual user's perceptions of Timeline, not necessarily based on the actual interface changes that were made.

\section{Secondary Appraisal: What can I do about it?}

Secondary appraisals of what can be done about a stressful situation are characterized with high or low levels of control over the situation [11]. We found both types of secondary appraisals in our data set. The majority (57\%) of comments tended to reflect low-levels of control. These users felt that they had little or no voice when it came to Facebook interface changes:

"Facebook is FREE! You do not 'own' it. It's a service provided to you for free. YOU do not have the right to make any demands." Trish, Comment \#127

In contrast, $43 \%$ of the comments reflected high levels of perceived control. These comments tended to be more positive about the changes:

"The timeline sounds great eh! :) What an awesome way to keep track of EVERYTHING that YOU want to SHARE :)," Jamie, Comment \#59, 5 Likes

Figure 3 depicts the overall relationship between primary and secondary appraisals in our data set. This graph is based on 642 comments that were coded with both a primary and secondary appraisal. It shows the percent of comments that depicted either high or low perceived control (secondary appraisals) for each type of primary appraisal. Irrelevant and positive appraisals tended to be accompanied 


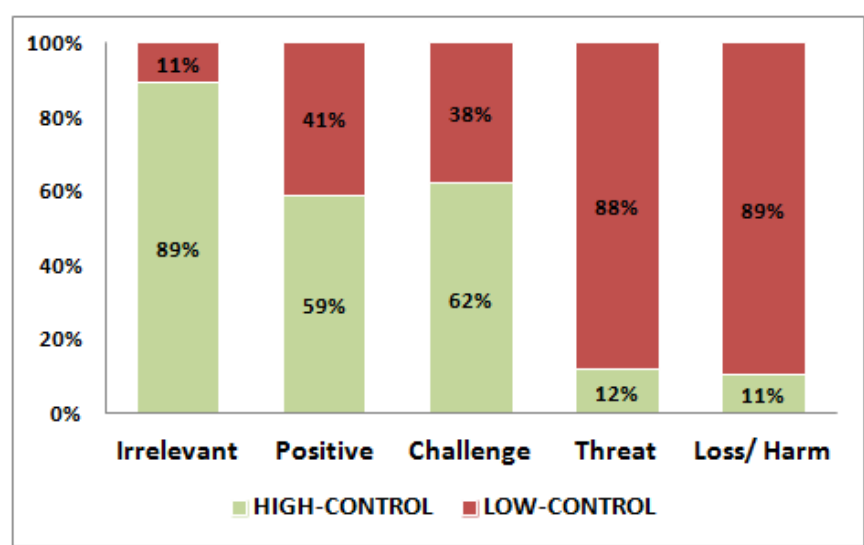

Figure 3: Primary versus Secondary Appraisals

with higher levels of perceived control. Loss/harm and threat stress appraisals tended to be associated with lower levels of perceived control. However, when individuals perceive a challenge, they tended to have higher levels of perceived control than the other types of stress appraisals. This finding is consistent with coping theory, which defines a challenge as a stressful situation that has the potential for positive outcomes and tends to be associated with higher levels of control [11]. Overall, Facebook users who perceived lower levels of control over the transition to Timeline tended to be more stressed.

\section{Coping Strategies}

Primary appraisals of what is "at stake" and secondary appraisals of perceived control work together to determine the amount of stress imposed on an individual. Individuals must decide how they are going to cope in order to reduce this stress [11]. Coping strategies can vary along two dimensions: First, they can be either problem-focused or emotion-focused. Second, coping strategies can be an attempt to alter either the environment or the individual [11], in this case, the user. We coded a total of 848 coping strategies within 753 comments. Figure 4 depicts the coping strategies that emerged in our data set, as they varied along these two dimensions. Based on our analysis, user adaptation strategies tended to be slightly more problem-focused $(51 \%)$ than emotionally-focused (49\%). Users focused more on trying to change the environment (64\%), as opposed to trying to change themselves (36\%). The following sections will go into more details about the four profiles of coping strategies.

\section{Emotion-Environment Focused Coping}

Complaints about Facebook Timeline were, by far, the most prevalent (33\%) coping strategy that we observed in our data set. Facebook users overwhelmingly used the blog to voice their displeasure over the launch of Timeline:

"Facebook, you're not near as smart as you think you are...Everything you do to try to simplify things only complicates things more. Every attempt you make to

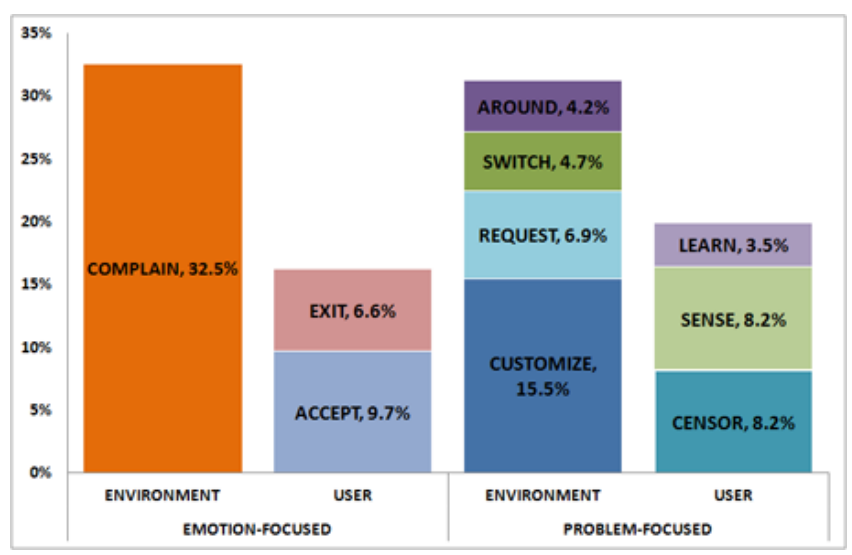

Figure 4: Coping Strategies

improve things inevitably ends up in a HUGE step backwards...” Declan, Comment \#903, 76 Likes

While some of the complaints were civil, many of them became irate:

\section{“FUCKBOOK !!!I HATE..” Wulan, Comment \#1066}

Even though it seemed like some users perceived a high level of control over Facebook, this tended to be an illusionary sense of control that only served to frustrate them further when they realized that Facebook was taking away rights that the user believed that they were entitled. These Facebook users had a strong sense that they were the user community (not the products) of Facebook. Therefore, Facebook would fail without their continued use and customer loyalty:

"they have PLENTY of obligations to us. we are the customers! remember how myspace died??? dont think our opinion doesnt matter.” Taliesin, Comment \#121

In general, complaints were emotionally charged criticisms directed at Facebook. These comments showed users' stress and frustration to both Facebook and other users.

\section{Emotion-User Focused Coping}

Another coping option was to alter the way users felt internally about the transition to Timeline (17\%). In these cases, users often felt a low sense of control over the situation and were resigned that they could not change Facebook Timeline. Therefore, they had only two available coping strategies: To accept it or to leave.

Accepting Timeline by adapting to the change was either accompanied with an evolutionary view of change as necessary for survival (in this case innovation) or associated with a sense of resignation due to lack of control:

"change is inevitable and its going to happen so lets stop bitching about something we get completely free," Brandon, Comment \#1,050, 20 Likes

Exiting Facebook to avoid transitioning to Timeline was another emotion-focused coping strategy. A number of Facebook comments took the standpoint that if someone did 
not like the Timeline changes, they should just leave. Simply leaving Facebook without going elsewhere would require the user to give up social networking altogether. Therefore, suggesting that another user should leave, go back to Myspace, or build their own SNS if they did not like Facebook, represented a definite lack of control and somewhat of a deliberate irony. These Facebook users often pointed out that Facebook was a free service. If users were not happy with it, they should just leave:

"You signed up to the site and agreed to it's terms and conditions of it allowing you to use it's site. Please see the deactivate button.” Kiki, Comment \#75, 3 Likes

\section{Problem-Environment Focused Coping}

A number of comments (32\%) suggested that users felt that they had high levels of control which they translated into action in order to gain mastery over Facebook. They did this through customizing the interface (16\%), making requests $(7 \%)$, threatening to switch SNSs (5\%), and working around Timeline features (4\%).

Customizing the new interface by using built-in settings was one way that users adapted to Timeline. To some extent, the customizations served to disable new features that users did not like:

"yall are stupid, you can [disable] certain features as always, stop hating,” Christopher, Comment \#498

However, in other cases, Facebook users started to experiment with the various settings and realized that the Timeline interface was highly customizable to their needs:

"I am finding that I can choose whom to share certain info with -- which is comforting to me. For example, my friends don't really like playing games and are tired of seeing all the game activity on my wall/profile. I can restrict my "game playing" to just my game players..." Melody, Comment \#633

Requests were slightly different than complaints because these comments suggested specific things Facebook could do to address users' stress levels. In most cases, these requests were desperate pleas or angry demands to go back to the old Facebook:

\section{“PLZ change fb back :(," Jordan, Comment \#942, 51 Likes}

However, some of the requests were more constructive solutions for how Facebook could have better handled the transition to Timeline:

"realistically speaking, alot of ppl out there are not technically inclined. their brains are not wired for techy stuff. $i$ think FACEBOOK should provide options available on the site that allows ppl to conform their page to their level." Dawn, Comment \#815

Threatening to switch to other SNSs, such as Google+, was another way of solving the problem. These users realized that they were not dependent on Facebook as their only option for socializing online. A total of 80 comments compared Facebook to other SNS websites. Seventy-two percent of the comments about Google+ saw it as a viable substitute and preferred interface over Timeline:

"TODAY FACEBOOK WILL END,, GOOGLE+ WILL START, AND A NEW ERA HAS BEGUN HAHAHA LOL .. GOOGLE+ IS VERY SIMPLE TO USE, " Vinci, Comment \#139

However, $28 \%$ of comments suggested that Timeline was Facebook's response to Google+, which they were not fond of:

"I HATE THE NEW FACEBOOK LAYOUT !!!! ALL FEATURE JUST SAME AS GOOGLE+... SHAME ON FACEBOOK, "Wulan, Comment \#57

Almost all the comments about Myspace were negative, warning to Facebook to not make the same mistakes:

"YOUR MAKING SHIT TOO PUBLIC AND LAME MYSPACE WANNA BE. NOTICE MYSPACE ISn't POPULAR ANYMORE WONDER WHY?" Brittany, Comment \#956, 18 Likes

A few comments also compared Facebook to other social networking alternatives, such as Twitter, Diaspora, Clicks, and Multiply. These Facebook users realized that they had options other than Facebook, which gave them a higher sense of control over how they social networked.

Workarounds allowed users who were unsatisfied with the built-in capabilities of Timeline ways to override aspects of the interface. Many of the workarounds were focused at getting rid of Timeline altogether. A number of browser extensions were developed and posted to the blog in order to modify the Timeline interface. For example, a link to a Facebook page called "Get Old face book" ${ }^{1}$ " was posted at least 15 times. It pointed Facebook users to a website called "Timeline Remove." Other browser extensions included "Social Fixer" and "FB Purity"." While the main goal of these extensions was to remove Timeline, some of them also provided users with higher levels of control over the Facebook interface:

"by using the BFB (Better Facebook) [extension] that Matt made. It let's u take away and add almost w/e u want. So ur FB looks how YOU want it to! It's pretty awesome!!!” Jessica, Comment \#931

In summary, these Facebook comments took a problemfocused approach toward changing Facebook in a way that would reduce stress about Timeline. In cases where Facebook users could not change Facebook directly, they found other SNS alternatives.

\footnotetext{
${ }^{1}$ https://www.facebook.com/0ldfaceb00k

${ }^{2}$ http://www.timelineremove.net/

${ }^{3}$ http://betterfacebook.net/

${ }^{4}$ http://www.fbpurity.com/disable-facebook-timeline.htm
} 


\section{Problem-User Focused Coping}

Some comments $(20 \%)$ suggested coping strategies that were problem-focused but focused on the user, instead of the environment. These comments reflected a high level of perceived control because users felt that it was just a matter of taking the problem into their own hands. These coping strategies included self-censorship (8\%), using common sense (8\%), and learning about Timeline (4\%).

One of the main blog threads was started by a Facebook user who was particularly stressed when she realized that Facebook had posted the entire trail she had run while using the Nike app:

"It might as well say "if anyone wants to mug me, I'll be walking alone through Central Park at 1:00 am, just east of the great lawn."” Amber, Comment \#275, 472 Likes

However, she received a torrent (over 100) replies that suggested ways that she could cope with this potential privacy threat. Self-censorship was one of the main ways that other Facebook users suggested. These Facebook users felt that it was the individual's responsibility to simply not post private information to Facebook:

"They can only steal what you put out. If you don't want your "friends" to know where you ran, don't post it..." Emily, Comment \#278, 31 Likes

Using common sense was another coping strategy for interacting with others through Facebook. For instance, Facebook users frequently suggested to others that if they were going to share personal information, that they not friend people that they did not trust:

"So don't add people you don't know? ... Who the hell stalks their close friends?" Kiki, Comment \#735, 8 Likes

Learning about the Timeline interface changes before making judgments about it was one positive way users could cope with the change. Some users were annoyed by people who were complaining about Timeline and emphasized that they should attempt to learn about the new interface before they whined about it:

"has anyone even sat down \& done some reading [about] the new features?? Too dumb maybe??" Josephine, Comment \#733, 49 Likes

A few Facebook users acknowledged the importance of personally learning about Timeline before passing judgment. Yet, one older user pointed out that learning to adapt to the new interface was somewhat of a challenge:

"I'm still learning the new system,,, a [little] harder for me being old and all after reading a lot of these post have learned so much...” Tina, Comment \#803

In summary, these coping strategies focused on the personal responsibility of users who had a high level of perceived control over how they adapted to Timeline.

\section{DISCUSSION}

\section{Perceived Control and User Appraisals}

As shown in Figure 3, there was a clear relationship between primary and secondary appraisals: Users who perceive higher levels of control tend to assess major interface changes more favorably than those who feel that they lack control. Hearkening back to coping theory, if an individual feels helpless in dealing with a stressful situation, the amount of stress can be great. Lazarus and Folkman further clarify that primary appraisals do not necessarily precede secondary appraisals [11]. Therefore, while we cannot confirm a causal relationship between primary and secondary appraisals in respect to Timeline adaptation, we can note a strong correlation between higher levels of perceived control and more positive appraisals of Timeline. An implication of this finding is that empowering SNS users with control could potentially increase users' positive response to major interface changes.

\section{Perceived Control and User Adaptation}

Earlier, user adaptation was defined as the efforts put forth to successfully cope with technological change within one's environment [2]. In our case, we examined SNS users' transition to Facebook Timeline. Coping theory defines adaptive coping strategies as efforts that lead to positive outcomes, such as life satisfaction/morale and higher functioning at work and socially [11]. For our purposes, adaptive coping would result in successful adaptation to Timeline. In contrast, maladaptive coping is defined as counterproductive, often reducing short-term stress at the expense of increased long-term stress $[8,11]$. Therefore, we consider any coping strategies that prolong or negate the successful transition to Timeline as maladaptive. For example, Baumer at al. suggest that leaving Facebook may give some users a sense of empowerment, but leaving may also cause strain on one's relationships [1]. Similarly, selfcensorship could be considered a type of social withdrawal that negates social networking with friends. Past research suggests that self-censorship within SNSs can lead to a sense of regret due to loss of authentic self [16].

Learning how to use Timeline, customizing it to meet one's needs, using common sense, making requests for changes, and ultimately accepting Timeline are the coping strategies from our data that could be construed as successful user adaptation to Timeline. Complaining, self-censoring, quitting Facebook, switching to another SNS, and using workarounds can be considered maladaptive coping because they may increase emotional distress and/or reduce the long-term, potential benefits of Timeline. Given this logic, approximately $67 \%$ of all coping strategies for stress appraisals that we observed could arguably be considered maladaptive (Figure 5). From this figure, we see that high levels of perceived control were often associated with adaptive coping strategies while low control was associated with maladaptive coping strategies. Users' desires to exert influence on how Facebook launched Timeline, but the 


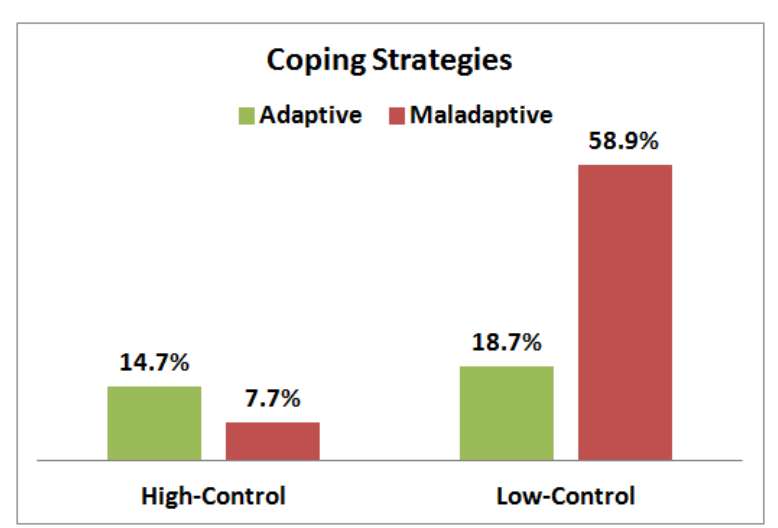

Figure 5: Adaptive versus Maladaptive Coping

inability to do so, tended to result in high levels of stress, often leading to emotionally charged, maladaptive coping responses. Thus, increasing SNS users' control perceptions could potentially facilitate users' successful adaptive coping to interface changes. For instance, when users were given the option to beta test Timeline, many were eager adopters. These users felt like they had more control, so they challenged themselves to learn all of the new features and customize the interface to meet their needs. Yet, many users became outraged when they found out that Timeline would become mandatory. These users were more emotionally reactive and spent their time protesting the change instead of embracing it. The opt-in strategy may have increased Facebook users' perceived levels of control and contributed to more positive appraisals and adaptive coping strategies. Figure 6 summarizes our high-level findings regarding user adaptation to Facebook Timeline. We applied coping theory to create this framework of user adaptation to major interface changes. We saw a consistent pattern between high levels of perceived control and users' adaptive coping to Timeline. Therefore, users' perception of control is a key factor in SNS user adaptation and needs to be examined further in future research.

\section{Collaborative Coping}

Our application of coping theory to user comments posted to the Timeline blog is unique because users were not coping individually; they were coping together. Coping theory suggests that the introduction of new information or feedback from others provides individuals with an opportunity to reappraise changes in the environment [11]. Past SNS research also highlights the importance of peer influence, finding that Facebook users who knew someone who had deactivated their account were three times more likely to deactivate their own Facebook accounts [1]. In our case, approximately $11 \%$ of the coping strategy comments posted to the Facebook blog urged users to either leave Facebook or switch to another SNS. Furthermore, users had no feedback from Facebook as a company, so they could only rely on new information (valid or invalid) from other users. In some cases, this created a bandwagon effect where extreme opinions became even more polarized and fairly deconstructive as users engaged in heated arguments. In

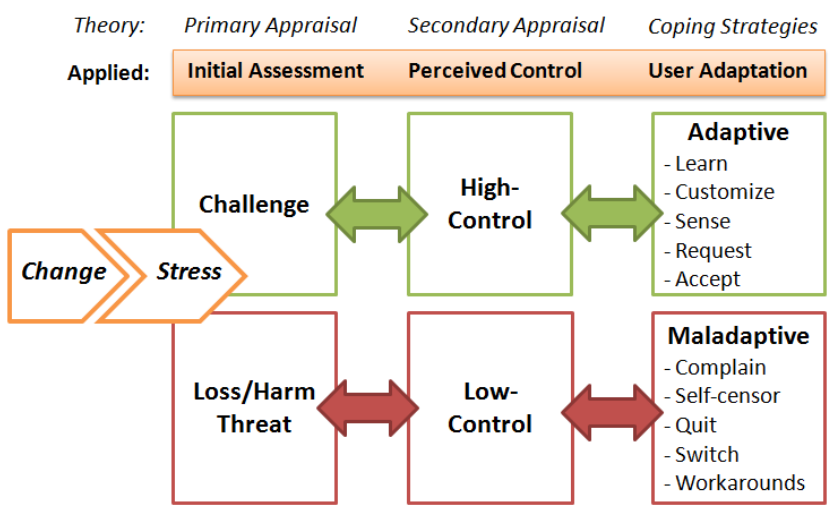

Figure 6: Framework of User Adaptation as an application of Coping Theory

instances like these, introducing a Facebook moderator may have helped deescalate some conflicts. Alternatively, in a smaller number of cases, Facebook users turned to other users as external resources [11] for understanding and adapting to Timeline. They asked questions about how to customize the new interface to meet their needs, such as adjusting privacy settings. Therefore, it may be beneficial in future releases for Facebook to assign facilitators who could also answer questions, correct misinformation, and give users the perception that their voices were being heard.

\section{Implications for Practice}

Direct implications for SNS designers are to proactively assess how interface-induced changes may affect end users and to embed appropriate options into the design and deployment process. A key point is that major interface changes induce psychological stress as well as technologyrelated stress. Our findings suggest that increasing users' perceived control over major interface changes may help facilitate users' adaptive coping strategies to these changes. Our work demonstrates the need for SNS designers to understand how users appraise a major interface change and highlights the importance of providing users with adequate control options so that they can successfully enact adaptive coping to the interface change. These design options may include, for example, communicating additional information about the new interface, so that users have a better understanding of its consequences; providing user choices through opt-in or opt-out mechanisms; providing better privacy control features; refraining from removing existing functionality; and facilitating communication among users for collaborative coping.

\section{Limitations and Future Research}

Our analysis was based on comments posted to the Facebook Timeline blog. Our methodology allowed us to unobtrusively analyze a diverse and large qualitative data set and capture users' in-situ reactions about the launch of Timeline, providing first-hand insights for understanding users' perceptions. However, there are some inherent weaknesses associated with this approach. First, commenting was deactivated prior to Timeline becoming 
mandatory for all users. Therefore, our analysis is largely based on users' reactions to the impending launch of Timeline, though some users had already transitioned (willingly or unwillingly). Second, comments posted to the blog may reflect strong and extreme opinions that are not representative of the typical Facebook user. Finally, this dataset is inadequate for providing us with deep insights regarding users' longitudinal behaviors; we did not confirm if users actually executed their stated coping strategies. In order to fill this gap in our research, we plan to do a followup study in which we send a follow-up survey via a private Facebook message to the 676 Facebook users that were captured in this data set. We believe that this follow-up study will give us further insights as to the long-term effects of major interface changes on SNS users.

\section{CONCLUSION}

This research demonstrates the need for HCI researchers and SNS service providers to understand how major interface changes are perceived by SNS users and to maintain user satisfaction by facilitating adaptive user coping during these times of change. While this research constitutes a step toward a better understanding of user adaptation in SNS, it raises questions that need to be addressed in future research. We hope that the ideas and preliminary results put forth in this paper will stimulate research on user adaptation in SNS, which remains a relatively unexplored area in our field.

\section{ACKNOWLEDGEMENTS}

The authors are very grateful to the $\mathrm{AC}$ and anonymous reviewers for their constructive comments and to Charlise Harris and Saijing Zheng for their assistance on this project. This research was partially supported by the U.S. National Science Foundation under grant CNS-0953749. Part of the work of Heng $\mathrm{Xu}$ was done while working at the National Science Foundation. Any opinion, findings, and conclusions or recommendations expressed in this material are those of the authors and do not necessarily reflect the views of the National Science Foundation.

\section{REFERENCES}

1. Baumer, E., Adams, P., Khovanskaya, V., Liao, T., Smith, M., Sosik, V. S. and Williams, K. Limiting, Leaving, and (re)Lapsing: An Exploratoration of Facebook Non-Use Practices and Experiences. In Proc. Conference on Human Factors in Computing Systems (2013).

2. Beaudry, A. and Pinsonneault, A. Understanding User Responses to Information Technology: A Coping Model of User Adaptation. MIS Quarterly, 29, 3 (2005), 493524.

3. boyd, D. Friends, friendsters, and myspace top 8: Writing community into being on social network sites. First Monday, 11, 2 (2006).
4. DeNinno, N. Facebook Timeline Mandatory Date Set for May 21. 2012, http://www.ibtimes.com/facebooktimeline-mandatory-date-set-may-21-final-rolloutcoming-next-week-report-698346.

5. Facebook. The Facebook Blog. 2011, https://blog.facebook.com/blog.php?post=10150408488 962131.

6. Facebook. Introducing Timeline: Tell your life story with a new kind of profile. 2011, https://www.facebook.com/about/timeline.

7. Facebook. Timeline. 2013, http://newsroom.fb.com/Timeline.

8. Horney, K. Our Inner Conflicts: A Constructive Theory of Neurosis. W W Norton \& Company Inc, New York, 1945.

9. Kincaid, J. Facebook News Feed Gets Smarter - And the Ticker Makes Its Big Debut. 2011, http://techcrunch.com/2011/09/20/facebook-news-feedgets-smarter\%E2\%80\%94\%C2\%A0and-the-tickermakes-its-big-debut/.

10. Lampe, C., Ellison, N. B. and Steinfield, C. Changes in use and perception of facebook. In Proc. Proceedings of the 2008 ACM conference on Computer supported cooperative work (2008), 721-730.

11.Lazarus, R. S. and Folkman, S. Stress, Appraisal, and Coping. Springer Publishing Company, New York, 1984.

12. Perez, S. Rolls Out Changes to Chat, Other Experiments, Leads to Problems. 2011, http://techcrunch.com/2011/08/11/facebook-rolls-outchanges-to-chat-other-experiments-leads-to-problems/.

13. Shi, P., Xu, H. and Chen, Y. Using contextual integrity to examine interpersonal information boundary on social network sites. In Proc. Proceedings of the SIGCHI Conference on Human Factors in Computing Systems, ACM (2013), 35-38.

14. SodaHead. Public Opinion Rejects Facebook's Changes. 2011, http://www.sodahead.com/united-states/publicopinion-rejects-facebooks-changesinfographic/question-2175115/.

15. Solove, D. J. A Taxonomy of Privacy. University of Pennsylvania Law Review, 154, 3 (2003).

16. Wisniewski, P., Lipford, H. and Wilson, D. Fighting for My Space: Coping Mechanisms for SNS Boundary Regulation. In Proc. Conference on Human Factors in Computing Systems (2012).

17.Zheng, S., Shi, P., Xu, H. and Zhang, C. Launching the new profile on facebook: understanding the triggers and outcomes of users' privacy concerns. In Proc. Proceedings of the 5th international conference on Trust and Trustworthy Computing, Springer-Verlag (2012), 325-339. 